\title{
Green hospital - A necessity and not option
}

\author{
Shipra Kumari ${ }^{1 *}$, Rajeev Kumar ${ }^{2}$ \\ ${ }^{1}$ Tutor \& PhD Scholar, ${ }^{2}$ Professor, ${ }^{1}$ Dept. of Health Administration, ${ }^{2}$ Dept. of Forensic, ${ }^{1}$ Faculty of Commerce and Management SGT \\ University, Gurugram, Haryana, India, ${ }^{2}$ Shaheed Hasan Khan Mewati Government Medical College, Haryana, India
}

\section{*Corresponding Author: Shipra Kumari}

Email: ritukyam@gmail.com

\begin{abstract}
Introduction: There is no countering the fact that in the latter half of the $20^{\text {th }}$ century humans have tampered with the ecosystem as has never been done before. Healthcare sector, through its consumption of a large number of resources and generation of an array of wastes, has itself become a public health concern. According to Indian Green Building Council, a green hospital building can be defined as one which enhances patient well-being, aids the curative process, while utilizing natural resources in an efficient, environment-friendly manner. Hospitals should be leading the way in providing patients the best quality of service and within the environment's safety. Sick people should have the greenest buildings of all.

This article aims to understand the basics of green hospitals, their various functions, the need to implement these ideas in hospitals rendering them environment and patient friendly, to identify the factors that affect the quality of green hospital design and to inform future green hospital designs.

Methodology: A systematic search was conducted to understand the broad issues of climate change, green hospitals and environmental sustainability. Information from green hospitals that are presently operating in India and abroad were collected and compiled to know the impact of implementing such measures in the economy of the hospital, recovery time of the patients and saving environment. Important reports and articles were collected in full text for further reference.

Result: By observing various green hospital's data, these strategies reduce buildings' operating costs by $8.9 \%$, increase building value by $7.5 \%$, a $6.6 \%$ return on investment, increase occupancy ratio by $3.5 \%$. The relationship between improved indoor air quality and positive health impacts on illness, including asthma, flu, sick building syndrome, respiratory problems and headaches, the improvements ranged from 13.5 to $87 \%$.

Conclusion: Healthcare facilities in India and around the world are paving the way and we can say that high quality patient care and environmentally sustainable health facilities are not mutually exclusive and that 'green hospital' is not just a vague concept but a reality worth emulating.
\end{abstract}

Keywords: Green hospital, Environment, Energy saving, Sustainable, Health care.

\section{Introduction}

Green building principles are revolutionizing building practices and are emerging as a response to growing concern over pollution and environmental damage, increasing awareness and acceptance of climate change, decreasing resources, increasing cost of energy and increasing demand for sustainability in building design and construction. Such contemporary approaches encourage environmentally responsible and resource efficient decisions by accounting for requirements throughout a building's life-cycle; i.e., considering the entire cycle from design through to construction, operation, maintenance, renovation, and demolition. In recent years, there has been an emerging subset of green design that has been revolutionizing hospital design by employing sustainable technologies, energy saving systems, and recyclable or renewable resources and materials. Within hospitals and healthcare facilities, the impact of the environment on users is more important than in offices or other commercial environments, because of the intention to create a place of healing and recovery. ${ }^{1}$

Hospitals should be leading the way in providing patients, experience. Sick people should have the greenest buildings of all. Hospitals are also particularly complex and provide unique building challenges healthcare facilities are most often multiple-building campuses of varying ages, conditions, and systems, and construction frequently occurs adjacent to occupied buildings. Sustainability trends are gaining tremendous momentum in the healthcare industry. In addition to green building initiatives like building for maximum energy efficiency and reducing the use of potable water, eco-friendly work tools and furniture are integral in any effort to achieve maximum "green" in a healthcare environment. What's more, eco-friendliness in the healthcare industry may cease to be an option-and instead, become a requirement as environmental awareness and the benefits of green building spreads. ${ }^{2}$

There is no countering the fact that in the latter half of the $20^{\text {th }}$ century humans have tampered with the ecosystem as has never been done before. Healthcare sector, through its consumption of a large number of resources, construction and operation of large and small, but complex establishments, employment of sophisticated energy-intensive technologies and generation of an array of wastes, has itself become a public health concern. ${ }^{3}$ In India the commercial sector, which includes the healthcare sector, consumes $7.58 \%$ of the total electricity. ${ }^{4}$ According to Central Pollution Control Board (CPCB) of India, the country generates approximately 1.48 million tons of healthcare waste per year. ${ }^{5}$

This article aims to understand the basics of green hospitals, their various functions, the need to implement these ideas in hospitals rendering them environment and patient friendly, to identify the factors that affect the quality of green 
hospital design and to inform future green hospital designs. This article is going to discuss environmental, economic, health and community benefits of sustainability in the healthcare industry.

\section{Definition}

There are many definitions of a Green hospital. Office of the Federal Environmental Executive defines a green or sustainable building as "the practice of increasing the efficiency with which buildings and their sites use energy, water, and materials, and reducing building impacts on human health and the environment, through better siting, design, construction, operation, maintenance, and removalthe complete building life cycle". ${ }^{6}$

United States Environmental Protection Agency defines green building as, "the practice of creating structures and using processes that are environmentally responsible and resource-efficient throughout a building's life-cycle from siting to design, construction, operation, maintenance, renovation and deconstruction. This practice expands and complements the classical building design concerns of economy, utility, durability, and comfort. Green building is also known as a sustainable or high-performance building". ${ }^{7}$

According to Healthcare without Harm, "A green and healthy hospital is the one that promotes public health by continuously reducing its environmental impact and ultimately eliminating its contribution to the burden of disease. A green and healthy hospital recognizes the connection between human health and the environment and demonstrates that understanding through its governance, strategy and operations. It connects local needs with environmental action and practices primary prevention by actively engaging in efforts to foster community environmental health, health equity and a green economy". ${ }^{8}$

According to Indian Green Building Council, a green hospital building can be defined as one which enhances patient well-being, aids the curative process, while utilizing natural resources in an efficient, environment-friendly manner. ${ }^{9}$

WHO has defined green hospital as a hospital, which is responsive to local climate conditions with optimized energy use. $^{10}$

\section{History of Green Hospitals}

The first effort made in this direction was the United Nations Conference on Human Environment, held in 1972 at Stockholm. Within the declaration of this conference it was stated that, "The protection and improvement of the human environment is a major issue which affects the well-being of people and economic development throughout the world, it is the urgent desire of the people of the whole world and the duty of all governments". ${ }^{11}$

World Commission on Environment and Development Report, also called Brundtland Report, published in 1987 realized that 'Environment' and 'Development' are not separate challenges, but are inexorably inked in a system of cause and effect. The report defined 'sustainable development' as, "a process of change in which the exploitation of resources, the direction of investments, the orientation of technological development and institutional change are all in harmony and enhance both current and future potential to meet human needs and aspirations". ${ }^{12}$

The United Nations Conference on Environment and Development, known as The Earth Summit, organized in Rio de Janeiro in 1992, resulted in Agenda 21 and the Rio Declaration of Environment and Development. ${ }^{13}$ Agenda 21 was a comprehensive blueprint for global action in all areas of sustainable development, while the declaration consisted of 27 principles intended to promote sustainable development around the world. ${ }^{14}$

The concept of developing sustainable green buildings received a further boost with the introduction of Triple Bottom Line (TBL) an approach, which was introduced and popularized by the green business guru - John B Elkington in the mid-1990s. ${ }^{15}$ TBL approach tends to measure the business performance in three key areas: economic, social and environmental thereby suggesting that a corporation that lacks social and ecological integrity shall not remain financially viable in the long run due to high operational cost and low customer loyalty. ${ }^{16}$ According to TBL approach, the primary goal of designing a green building should be to reduce the use of resource ${ }^{17}$ such as land, water, energy, and supplies so that the people who live, work, learn and heal in green buildings will be healthier, happier and more productive. ${ }^{13}$

These movements are precursors for the establishment of 'green building councils' in different countries bolstering the fact that green healthcare is inseparably connected to the global challenges of climate change, toxification, freshwater shortages and resource depletion. United States Green Building Council (USGBC) is one of the earliest such councils which was established in the year 1993. It is a membership-based, non-profit organization that promotes sustainability in how buildings are designed, built, and operated. World Green Building Council (World GBC), which was formally established in the year 2002, is an alliance of national green building councils in more than one hundred countries. World GBC helps to standardize and promote green building practices all over the world through its wide membership. ${ }^{18}$

Confederation of Indian Industry (CII) established Indian Green Building Council (IGBC) in the year 2001 with a goal to promote the development of climate-neutral and sustainable buildings, so that India becomes a global leader in the sustainable built environment by $2025 .{ }^{19}$ Developing new rating systems, certifications, conducting training programmes and organizing an annual Green Building Congress are the various services offered. IGBC is licensed by US Green Building Council to give Leadership in Energy and Environment Design (LEED) certifications to buildings in India.

With the increasing awareness about the benefits of 'going green', several green building rating systems have been developed. More than six building rating systems are being used in different regions of the world, most notable are: Leadership in Energy and Environmental Design or LEED 
(United States, Canada, China and India), Building Research Establishment Environmental Assessment Methods or BREEAM (UK and Netherlands), Green Star (Australia, New Zealand and South Africa), Comprehensive Assessment System for Building Environmental Efficiency or CASBEE (Japan) and Green Mark Scheme (Singapore). ${ }^{17}$

LEED rating system, developed by USGB and launched in 2000, helps to measure the sustainability of different buildings including hospitals. LEED ratings are classified into four categories: LEED-certified, Silver, Gold and Platinum with platinum being the highest rating. Buildings are rated in five key areas in order to achieve LEED certification, the key areas being: sustainable site development, water savings, energy efficiency, material selection and indoor environment quality. ${ }^{20}$

About 28 hospitals in the United States have Gold and Platinum LEED certifications. ${ }^{21}$ Kohinoor Hospital in Mumbai - a 150-bedded multispecialty hospital - became the first hospital in Asia and second in the world to achieve LEED platinum certification under Indian Green Building Council. $^{20}$

\section{Elements of green hospital Green building design}

While there are many green design principles, the core concepts often focus on the production and use of energy, water resources, the use of solar energy to improve electricity generation and reduce use of electricity, improved aeration, climatic features, and the long-term impact building materials the consideration of the lifecycle of the facility. Green building techniques were developed during the world's energy crisis in 1970's and have been used since. There is wide recognition that green design can bring financial benefits during both the construction and operational phases. Green building strategies reduce buildings' operating costs by 8.9 percent, increase building value by 7.5 percent, realize a 6.6 percent return on investment, increase occupancy ratio by 3.5 percent, and increase rent ratios by 3 percent. $^{1}$

Rapid construction of healthcare infrastructure puts a great burden on the local and indigenous building material supplies and methodologies beyond their sustainable capacities. Healthcare facilities can become environmentally sustainable by siting hospitals near public transportation routes, using local and regional building materials, planting trees on the site, and by incorporating design components like day lighting, natural ventilation, alternative energy, water harvesting and green roofs. Carnegie Mellon University Center for Building Performance and Diagnostics identified 17 international studies that document the relationship between improved indoor air quality and positive health impacts on illness, including asthma, flu, sick building syndrome, respiratory problems and headaches, the improvements ranged from 13.5 to $87 \%$. The Sambhavna Trust Clinic, founded in 1996 in Bhopal is a green structure in every sense. It has been constructed from local materials, and is low-cost and durable. It combines beauty with function while blending-in with the landscape and is passively cooled, day lit, harvests the rainwater and uses solar water heaters. ${ }^{3}$

\section{Construction materials and practices}

A strong focus should be placed on integrating recycledcontent building materials and locally harvested and manufactured materials into the project.

Reducing PVC use TPO (Thermoplastic polyolefin) E star roof ENERGY STAR qualified roof products reduce the amount of air conditioning needed in buildings, and can reduce energy bills by up to 50 percent. Low or no formaldehyde and low or 110 VOC indoor finish materials.

\section{Volatile Organic Compounds (VOCs)}

Volatile organic compounds (VOCs) are emitted as gases from certain solids or liquids. VOCs include a variety of chemicals, some of which may have short and long-term adverse health effects. Concentrations of many VOCs are consistently higher indoors (up to ten times higher) than outdoors. VOCs are emitted by a wide array of products numbering in the thousands. Examples include: paints and lacquers, paint strippers, cleaning supplies, pesticides, building materials and furnishings, office equipment such as copiers and printers, correction fluids and carbonless copy paper, graphics and craft materials including glues and adhesives, permanent markers, and photographic solutions. ${ }^{2}$

\section{Life-cycle impact of building materials}

Considering life-cycle impact of building materials reduces the environmental impact of the materials and products employed across the life-cycle of the facility; priority is given to resources with smaller impact on the environment and energy usage. This focus on the life-cycle begins as early as the extraction or manufacture of the materials or products to be used. The final materials must be non-toxic, have additional features, be easily saved and recycled at the end of a buildings life-span, and reduce costs for activities undertaken by building services providers. ${ }^{1}$

\section{Energy}

Reducing energy use is a key focus for green designers, especially when considering ventilation and lighting. Maximizing the use of natural lighting during the day can reduce energy costs and improve the atmosphere for buildings' users. ${ }^{1}$

Energy Star reflective roof, with high R-value (R-30). A reflective roof and insulation in the roof and exterior walls to minimize heat gain in the building, which also minimizes energy usage. To have minimum annual heating and cooling cost, it is recommended to use a minimum $\mathrm{R}-30$ roof insulation. Energy-efficient glazing: low E (short for emittance) glass that contains an invisible metal coating that sandwich between the layers of glazing, which causes the glass to be reflective. They keep the building warmer in the winter and cooler in the summer. Under-floor air distribution in non-clinical, non-patient areas requires less fan power than above-ceiling ducts. Daylighting is used primarily to light the central, two stories, and entry space. Lighting does not affect adjacent neighbourhoods. Up lighting, bleeding and light pollution is non-existent. Day-lighting is maximized in 
occupied space. Sensors in rooms shut off lights when no one is present. When a patient opens a window for fresh air, a sensor notifies the AC system to shut off room's air conditioning. In addition, to capture as much natural light as possible, hospitals should be constructed on the basis of sunrise and sunset directions. Motion and natural light sensors shut off unneeded lights. Natural Light hubs and spoke design interior court yards that bring natural light throughout the building. In addition, the courtyards are a great way-finding tool for young patients who can't read signs yet, and provide a place for families to relax and preoccupy themselves. The hospitals should feature a combination of natural and artificial light. ${ }^{2}$

Smaller measures such as switching to compact fluorescent and light-emitting diode (LED) light bulbs, turning thermostats down by just a few degrees in the winter or up a little in the summer, purchasing energy-efficient products, reducing "stand- by" energy use, and retrofitting buildings to cut energy waste can have a major impact. The Sir J.J. Hospital in Mumbai launched an awareness campaign to reduce energy use throughout the hospital. The campaign included slogans, posters and other tools and measures such as, systematically turning off office equipment, using natural light during daylight hours in hospital corridors, and plugging leaks in the air conditioning. The project resulted in a total energy savings of $812000 \mathrm{kWh}$ from 2002 to 2004, and a cost saving of US\$90000. ${ }^{3}$

\section{Improving aeration and quality}

Improving aeration in all occupied areas in facilities and striving to attain high air quality through effective construction protocols and designs (e.g., to remove dust, airborne toxins, and other materials) and through material specifications (e.g., requiring materials to contain no undesired chemical substances or compounds that may be hazardous). ${ }^{1}$

Newly constructed, renovated, and remodelled buildings can emit air pollutants from various components used in the construction process such as adhesives, paint, carpet, furnishings, etc. In an effort to remove indoor air pollutants, buildings should undergo a pre-occupancy flush-out where a large amount of tempered outdoor air is forced through the building via the ventilation system. A flush-out typically lasts between 3 to 30 days depending on the building material and furnishings, allowing the majority of pollutants to be removed from the building prior to occupancy. ${ }^{2}$

\section{Solar heating and cooling}

Passive solar heating and cooling is supported by site design to select and use a site that maximizes passive solar heating and cooling opportunities. The site must conserve natural resources (e.g. trees and wildlife habitats) and minimize land interference and erosion. ${ }^{1}$

Parking lot trees and reflective surface pavement and roof materials reduce the heat-island effect.

\section{Water-use}

Improving water-use is achieved through various mechanisms of green design focused on efficient water use; e.g., rainwater harvesting, use of fixtures that conserve water, waste water treatment and recycling, green roofing, and control of storm water release. For example, harvesting rainwater requires designs that raise the $\mathrm{pH}$ of collected water and the final treatment and elimination of waste water. This reduces the burden on municipal infrastructure to supply clean water. Hospital systems often operate for decades and therefore require well-constructed and efficient systems. ${ }^{1}$

Waterless urinals and efficient sensor fixtures help in reducing water wastage. The hospitals should be focused on reduction of water use through xeriscaping (landscaping that does not require supplemental irrigation), low-flow fixtures. These strategies rely on the use of native and drought-tolerant vegetation, reduce the hospital's irrigation water requirements by more than 50 percent. Xeriscaping is a good example of how the green approach, while initially more costly, becomes the smartest environmental and economical approach over time. Reclaimed water is used for irrigation. ${ }^{2}$

Healthcare facilities utilize vast quantities of water. Climate change, with its accompanying impacts of drought, glacier melt and aquifer depletion, will exacerbate water scarcity. Health facilities can conserve water by harvesting rainwater and recycling water for non-drinking purposes. At Bhopal's Sambhavna Trust Clinic, for example, rainwater is harvested during the monsoon season and stored for use during the dry months of the year, recycled, or grey water is used for irrigation on hospital grounds. ${ }^{8}$

\section{Environment}

Integration of climatic- and site-features ensures that a green structure must not only be sustainable itself but it must also ensure the design integrates important elements of sites' climatic conditions. Fundamental elements integrated into green design are the site's geology, hydrology, ecosystem, regional climate, and the specific micro-climates. Such considerations yield increases in user comfort levels and decreases in both energy consumption and operating cost. Both location and design should encourage sustainable and healthy transport options (e.g., use of mass transit, cycling, or walking). ${ }^{1}$

\section{Waste Management}

Most of the hospitals, nursing homes and clinics, in both public and private sector, in India have no systems for effective and safe disposal of their waste, which finds its way to the open bins on the roadside or the low-lying areas or is discharged into the water bodies. A $10 \%$ to $15 \%$ of the total waste generated in a healthcare facility is hazardous waste, which is harmful to the environment. Improper disposal of such waste, especially as open dumps, attracts a host of disease vector, release unpleasant odours and may also lead to transmission of diseases.

Health facilities can cut waste and emissions through composting, recycling, better purchasing (minimizing packaging, using reusable rather than disposable products, 
and buying recycled products), and minimizing waste transport. The infected plastics can be landfilled after disinfection, rather than incinerated, since burning plastic produces greenhouse gases and toxic pollutants such as dioxins and furans. Embassy Medical Centre Colombo, Sri Lanka converts sewage from the hospital and Colombo's underdeveloped neighbourhoods into carbon-neutral renewable energy using a high-temperature thermophilic anaerobic digester. This hi-tech compost system will naturally create bio-methane that will be polished into BioNatural Gas (BNG). The BNG is then used in a co-generation plant to power the hospital and water purification systems. ${ }^{3}$

\section{Barriers to create "green hospitals"}

Greg L Roberts ${ }^{22}$, in his article "shades of green" has cited different barriers to green health facilities, which are as follows:

1. System redundancy: Requirement of secondary and tertiary backup systems to make sure that operations do not cease during emergencies.

2. Regulatory compliance- Health and safety regulations and building codes became a barrier for hospitals to adopt sustainable practices.

3. Operational hours: Health facilities function uninterruptedly throughout the year.

4. Infection control: Hospitals require strict infection control protocols which often are against sustainability practices.

5. Ventilation rates: More frequent air changes are required in a hospital as compared to other commercial office spaces.

6. Accreditation and licensing demands: Compliance with central, state and accreditation standards might prevent facilities to make environmentally sound choices.

7. Intense energy and water use: Health care uses 2.1 times more energy per square foot than commercial buildings, and hospitals typically use $80-150$ gallons of water per bed per day.

8. High-volume waste stream: About $0.5 \mathrm{Kg}$ of hazardous waste is generated per bed per day.

9. Chemical use: Hazardous chemicals used to clean and disinfect, sterilize equipment, treat certain diseases and for laboratory research and testing can be toxic and hazardous.

10. Life cycle: The exteriors of hospital buildings can last long, but interiors require renovations every few years.

A survey conducted by Health Facilities Management (HFM) in collaboration with the American Society for Healthcare Engineering (ASHE) and the Association for the Healthcare Environment (AHE) in 2013 identified many barriers/ challenges that prevent hospitals from adopting environmentally sustainable practices; the top five among them are: competing investment or spending priorities, inadequate staffing for initiatives, underfunded operations and maintenance budgets, perceived higher costs over traditional materials or systems and time limitations. ${ }^{23}$

\section{Conclusion}

Modern health care facilities are highly resource intensive. In their bid to provide high quality care to their patients, they are damaging the environment. Hospitals operate non-stop throughout the year, they utilizing sophisticated and modern medical technologies, and perform complex medical procedures, which require adequate lighting and temperature. This cannot be accomplished without more electricity. As the implications of climate change become apparent, water is becoming scarcer but hospitals require more water for cleaning, laundry, hand washing, food preparation, drinking. Unsustainable and inefficient buildings, unsafe disposal of hospital waste and untreated sewage, heavy reliance on processed foods and a fleet of fuel guzzling vehicles are just a few factors that increase the health sector's carbon footprint, thus making the environment sick.

Despite the challenges, today's health care institutions are finding new ways to incorporate green design strategies into new construction to speed healing, not only of patients, but also of the planet. The first challenge involves finding eloquent ways to identify appropriate strategies and measure their effectiveness.

More than an optimization of any single component, sustainable design and construction represents the integration of materials and methods that, together, create the physical manifestation of a building. The entire life cycle of building materials and products, as well as the building as a whole relative to its physical, environmental and human contexts on the local, regional and global scales, must be evaluated for environmental and health considerations.

According to our understanding of green hospitals, we could conclude that a checklist for a sustainable design will include:

\section{Economic considerations}

Labour skills and training Regional economic benefits. Savings through energy reductions Life cycle cost planningcapital cost vs. maintenance burden.

\section{Environmental considerations}

Use of and specification of sustainable responsible materials Energy efficiency in design. Water use management-in construction and design. Carbon reduction-efficiency in plant Waste management in reuse and minimizing over-ordering. Recycling throughout. Managing noise, vibration, transport disruption to local environs. Avoiding pollution locally during construction - water and airborne.

\section{Community consideration}

Consultation and presentation Health and safety on and around site. Managing disruption to ongoing hospital facilities. Holistic and best practice design-a healthy environment and faster healing. Supporting green initiatives goes beyond building design and materials. A sustainable facility that respects its fulltime and temporary occupants as well as the Earth, has the potential for better staff recruitment and retention, greater control over the spread of infection, better patient outcomes, and improved stature within the 
community. Small successes like an energy audit or move to a greener cleaning protocol may break down obstacles to greater innovations.

Healthcare facilities in India and around the world are paving the way and we can say that high quality patient care and environmentally sustainable health facilities are not mutually exclusive and that 'green hospital' is not just a vague concept but a reality worth emulating.

\section{Source of Funding}

None.

\section{Conflicts of Interest}

None.

\section{References}

1. Wood LC, Wang C, Rahmand HA, Nasirc NSJA. Green hospital design: integrating quality function deployment and end-user demands, J Cleaner Production. 2016;112(1):903-13.

2. Salehi F, Eslami SV. Green Strategies of Healthcare Design: Case Studies of Medical Centers, Sustainable Architecture Urban Dev. 431-46.

3. Dhillon VS, Kaur D. Green Hospital and Climate Change: Their Interrelationship and the Way Forward. J Clin Diagn Res. 2015;9(12):LE01-5.

4. Kapoor R, Kumar S. Energy efficiency in hospitals: best practice guide. New Delhi: United States Agency for International Development; 2011March. 41p.

5. Over 1 Million tonnes Medical Waste Headache for India. The Pharma Times Available from: http://www.thepharmatimes.in/index.php/news/general/nationa 1/237-over-1-million-tonnes-medical-waste-headache-for-india.

6. Howard JL. Federal commitment to green building: Experiences and expectations. Office of Federal Environmental Executive (US);89p 2003.

7. Bandhauer K, Gerber MA, Simon S, Smith S, Buffo C et al. Sustainable design and green building toolkit for local governments. Environmental Protection Agency (US); 2013 June. 100p. Report No.: EPA904B10001.

8. Karliner J, Guenther R. Global green and healthy hospitals agenda. Health Care without Harm; 2011 October, 41p.

9. Srinivas S. Technical Bulletin: Green Hospitals. Available from:

https://igbc.in/igbc/html_pdfs/technical/Green\%20Hospitals.pd

10. World Health Organization discussion draft Healthy Hospitals Healthy Planet Healthy People. Addressing climate change in health care settings, Geneva, Switzerland; 2009-28.

11. Sohn BL. The Stockholm declaration on the human environment. The Harvard Int Law J. 1973;14(3):423-515.

12. Brundtland GH, World Commission on Environment and Development (WCED). Our Common Future. Oxford: Oxford University Press; 1987.

13. Guenther R, Vittori G. Sustainable Healthcare Architecture. 2nd ed. Hoboken, New Jersey, USA: John Wiley \& Sons, Inc.; 2013

14. Burhenne-Guilmin F, Hassan P, Robinson NA. Agenda 21 and UNCED proceedings. New York: Oxford University Press; 1993.

15. Berkovics D. Alternative Management Observatory. Oxford; Capstone Publishing: 1999. Available from: http://appli6.hec.fr/amo/Public/Files/Docs/148_en.pdf.

16. Robert G, Guenther R. Environmentally responsible hospitals In: Marberry SD, editor. Improving healthcare with better building design. Health Administration Press. 2005;37-61.
17. Wu Z. Evaluation of a sustainable hospital design based on its social and environmental outcomes (MSc Thesis). Ithaka, New York: Cornell University;. Available from: http://iwsp.human.cornell.edu/files/2013/09/Ziqi-Wu-201119cxn60.pdf. 2011; 1-228.

18. Wikipedia contributors. Green Building Council (Internet). Wikipedia, The Free Encyclopedia; 26,07:55 UTC. Available from: http://en.

wikipedia.org/w/index.php?title=Green_Building_Council\&ol did $=648908264.2015$.

19. Indian Green Building Council (Internet) 2014. Available from:

https://igbc.in/igbc/redirectHtml.htm?redVal=showAboutusnos ign.

20. Rich CR, Singleton JK, Wadhwa SS. Sustainability for healthcare management: a leadership imperative. Abingdon, Oxon; Routledge: 2013. Available from: https://books.google.co.

21. Herman B. 28 Hospitals with Gold or Platinum LEED Certification. Becker's Hospital Review. (Internet) 2012. Available from: http://www.beckershospitalreview.com/lists/28-hospitals-withgold-or-platinum-leed-certification.html.

22. Roberts GL. Shades of green. healthcare facility management. 2011 January. Available from: http://www.hfmmagazine.com.

23. Burmabl B, Hoppszallern S. Shades of green. healthcare facility management. 2013 July. Available from: http://www.hfmmagazine.com

How to cite: Kumari S, Kumar R. Green hospital - A necessity and not option. J Manag Res Anal. 2020;7(2):4651 